\title{
O LETRAMENTO DOS INVISÍVEIS: A OPERACIONALIZAÇÃO DOS LETRAMENTOS POR ADULTOS NÃO ALFABETIZADOS
}

\section{THE LETTER OF THE INVISIBLE: THE OPERATIONALIZATION OF LETTERS BY NON-LITERACY ADULTS}

\author{
Renata Ferreira Rios ${ }^{1}$ \\ Kleber Ferreira Costa ${ }^{2}$ \\ Wellington Moreira Lopes ${ }^{3}$ \\ Universidade de Pernambuco - UPE
}

\section{RESUMO}

Pegar o ônibus, ler a bula de remédio, acessar redes sociais são atividades corriqueiras no cotidiano de sujeitos letrados em nossa sociedade, mas para o adulto não alfabetizado essas e outras práticas sociais são vivenciadas com momentos de resistência e (re) construção do modo de agir diante do novo. Nesse contexto, este artigo tem por objetivo investigar que mecanismos de letramentos são acionados pelos adultos não alfabetizados em meio à sociedade grafocêntrica, que permite sua interação com os multiletramentos. Esta pesquisa tomou por base os estudos de Soares (2005), Cavalcante Jr. (2009), Tfouni (2010), Bosi (2003) e outros, que a luz da abordagem qualitativa, de cunho exploratório nos levou a entender como adultos não alfabetizados operacionalizam os letramentos diversos em seu cotidiano.

PALAVRAS-CHAVE: Letramentos; Operacionalização; Adultos não-alfabetizados.

\section{ABSTRACT}

Take the bus, read the medicine package insert, accessing social networks are everyday activities of literate subjects in our society, but for the nonliterate adult these and other social practices are experienced with moments of resistance and (re) construction of the way of act before the new. In this context, this article aims to investigate which mechanisms of literacy are triggered by non literate adults in the midst of grafocentric society, which allows their interaction with multiletramentos. This research was based on the studies of Soares (2005), Cavalcante Jr. (2009),

\footnotetext{
1 Doutora em Linguística pela Universidade Federal de Goiás. Possui mestrado em Linguística pela Universidade Federal de Juiz de Fora. Graduada em Letras, Português e Inglês, pela Universidade Federal de Viçosa. Professora adjunta do curso de Letras da Universidade de Pernambuco - Campus Petrolina. Membro do grupo de pesquisa Itinerários Interdisciplinares em Estudos sobre o Imaginário (ITESI) membro do grupo de estudos e pesquisa em Ensino de Língua (GEPEL); E-mail: renatarios7@gmail.com /código ORCID http://orcid.org/0000-0001-64201432

${ }^{2}$ Mestre em Linguagem e Ensino - UFCG, professor assistente da Universidade de Pernambuco (UPE), Membro dos Grupos de Pesquisa: Grupo de estudo e pesquisa Linguagem em Contexto Educacional (GEPLCE) e Grupo de Estudos e Pesquisa em Educação Escolar e não Escolar no Sertão Pernambucano (GEPESPE); E-mail: kleber.costa@upe.br / código ORCID http://orcid.org/0000-0002-7525-9696

${ }^{3}$ Graduado em Letras / UPE campus Petrolina. Membro dos grupos de estudo: Grupo de estudos e pesquisa em educação escolar e não escolar no Sertão Pernambucano (GEPESPE) e Grupo de estudo e pesquisa em Linguagem em Contexto Educacional (GEPLCE). E-mail wellingtonmoreiralopes@,hotmail.com / código ORCID http://orcid.org/0000-0002-0739-5733
} 
Tfouni (2010), Bosi (2003) and others, that the light of the qualitative, exploratory approach led us to understand how non- literate adults operate the various literacies in their daily life.

KEYWORDS: Literacy; Operacionalization; Non literate adults.

\section{INTRODUÇÃO}

Segundo dados da Pesquisa Nacional por Amostra de Domicílios Contínua, do Instituto Brasileiro de Geografia e Estatística (IBGE, 2018), atualmente, o Brasil tem 11,5 milhões de analfabetos, ou seja, pessoas que não possuem o domínio da norma de leitura e de escrita de sua própria língua - que é determinada como padrão para a execução em suas práticas sociais -.

Neste sentido, surgiu esta pesquisa com o objetivo de investigar que mecanismos de letramentos são acionados pelos adultos não alfabetizados, nesta sociedade grafocêntrica, que permite sua interação com os multiletramentos.

\section{Alfabetização e letramentos: definindo conceitos}

A sociedade já passou por diversas revoluções que mudaram as esferas políticas e econômicas interferindo nas relações sociais e de poder nas sociedades, porém nenhuma revolução, no entanto, teve tanta influência no modo de como o homem vê o mundo como na revolução da/na escrita. O decorrer do processo de passagem de sociedades estritamente orais para comunidades escritas mudou a maneira de como o homem se vê no mundo e como o modifica. Na contemporaneidade, essas mudanças são ainda mais significativas com a chegada da internet e das relações multimídias do mundo moderno, quando passamos a ver assim, a escrita e a leitura, sobre perspectivas ainda mais importantes e revolucionárias que anteriormente não era habitual.

No entanto, diversos sujeitos que não foram escolarizados e alfabetizados pelo espaço escolar, não possuindo o domínio da leitura e da escrita normatizados, ainda assim, não foram excluídos dos letramentos e, com toda dificuldade em se inserir numa sociedade de múltiplos letramentos, são desafiados por diversos aspectos e costumes da cultura letrada em que estão imersos, para realizar suas práticas sociais independente do domínio da leitura ou da escrita.

Isso remete a reflexão feita por Tfouni (2010), quando aborda sobre os processos de Alfabetização, Letramento e Escolarização que possuem aspectos comuns que os perpassam, mas não são vistos integrados ou com ideia de conjunto, mesmo sendo interdependentes entre si,

\footnotetext{
Apesar de estarem indissolúvel e inevitavelmente ligados entre si, escrita, alfabetização e letramento nem sempre têm sido enfocados como um conjunto pelos estudiosos. Diria inicialmente que a relação entre eles é aquela de produto e processo: enquanto os sistemas de escrita são um produto cultural, a alfabetização e o letramento são processos de aquisição de um sistema escrito (TFOUNI, 2010, p. 11).
}

Como se observa, uma das primeiras perspectivas de estudo do domínio das formas de expressão escrita na nossa sociedade se refere ao processo de Alfabetização, o qual para diversos estudiosos ocorria diretamente relacionado ao processo de Escolarização. No entanto, é discordado por Jung (2007, p. 79), quando esclarece que "O conceito de alfabetização [...] é anterior ao conceito de escolarização", assim, o contato da criança com a língua se dá anteriormente ao processo de escolarização, processo esse que ocorre ainda na interação com a família, a comunidade e as brincadeiras em que ela está inserida. Dessa forma, esse processo surge a partir das relações estabelecidas com a língua, enquanto esse sujeito se enxerga como tal perante o mundo. 
Entretanto, ao definir o conceito de Alfabetização como "um sistema de conhecimento descontextualizado, validado através de desempenhos em testes" (JUNG, 2007, p. 84), ele (re) afirma o caráter diferenciador entre alfabetização e escolarização, confirmando porque esse termo (Alfabetização) foi intimamente ligado ao de Escolarização, visto que só ganha status e importância como tal a partir de testes de verificação de sua aquisição na escola, ganhando prestígio a partir dos diversos processos e mecanismos de verificação e de avaliação que ocorrem dentro do ambiente escolar, assim como defendido por Giroux ( 1983, p. 56, apud TFOUNI, 2010, p. 19): "A relação entre alfabetização e escolarização torna-se clara se considerarmos que, embora a criança possa primeiramente entrar em contato com a linguagem através de sua família, é principalmente na escola que a alfabetização se consuma".

Acreditou-se, por muito tempo, que alfabetização restringia-se ao domínio dos códigos e símbolos da nossa língua, bem como a união desses e a tradução. Pensar, no entanto, em um processo de alfabetização que acaba em si mesmo, sem nenhum processo social, sendo encarada como somente a decodificação de signos linguísticos, é banalizar toda a influência de uma escrita que é o produto cultural por excelência (TFOUNI, 2010, p. 12).

Teale (1982, p.559, apud TFOUNI, 2010, p.17), no entanto, separa o que para ele parece ser processos distintos, trazendo uma ideia muito mais ampla para a alfabetização ao refletir que "a prática da alfabetização não é meramente a habilidade abstrata para produzir, decodificar e compreender a escrita; pelo contrário, quando as crianças são alfabetizadas, elas usam a leitura e a escrita na execução das práticas que constituem sua cultura", fazendo, portanto, um processo de integração entre a leitura, a escrita e a cultura para poder desvendar o entorno social, evoluindo, assim, para domínios cada vez mais aprofundados de compreensão e de percepção do processo de alfabetização.

Também em Tfouni (TFOUNI, 2010, p. 17) encontramos esse diálogo com Teale (1982, p.559), ao propor que estamos imersos a níveis de alfabetização ao dizer: "talvez seja melhor não falar em alfabetização simplesmente, mas em graus, ou níveis de alfabetização", uma forma de perceber que sempre se estar evoluindo em níveis ou modalidades diferentes de compreender as práticas sociais de alfabetização, assim como defenderemos a ideia de nos referir a níveis de letramentos, da mesma maneira como temos os níveis de escolarização.

Surge então, com essa nova perspectiva para a alfabetização, diversos questionamentos que nos fazem refletir acerca do papel da leitura e da escrita nas sociedades modernas e como as práticas sociais inseridas intrinsicamente se relacionam com elas. O primeiro deles nos é trazido por Jung, quando questiona: "Por que pessoas alfabetizadas não necessariamente adquirem competência para usar a leitura e a escrita, para envolver-se com as práticas sociais da escrita?" (JUNG, 2007, p. 84) e por Tfouni em: "Pode-se encontrar em grupos não alfabetizados características que usualmente são atribuídas a grupos alfabetizados e escolarizados?" (TFOUNI, 2010, p. 26). Na busca por responder esses e outros questionamentos, que abarcassem de maneira satisfatória essa nova percepção de uso da língua, é que surgem os primeiros estudos sobre letramentos.

Nesse sentido, o que ocorreu, graças aos diversos estudos na área, foi uma expansão significativa na abordagem e na maneira de ver o letramento em sociedades tão centradas na escrita como as nossas, mas ainda com desafios imensos no uso da escrita e da leitura por parte dos falantes nativos da língua, assim como defendido por Donald Graves (1996):

[...] A definição de Letramento precisa[va] ser expandida. As escolas estão centradas em palavras. Não existe dúvidas de que as palavras são importantes, mas elas são apenas um tipo de manifestação da inteligência. Ao focarmos em palavras e excluirmos outras formas de expressão, estamos privando uma massa de crianças de darem suas valiosas contribuições à escola e à comunidade (GRAVES, 1996, apud CAVALCANTE JUNIOR, 2009, p. 38). 
Dessa forma, como defendido por Graves (1996), foi preciso (re) pensar um termo de letramento que tivesse uma concepção plural, assim como é a língua, como são os sujeitos falantes e as práticas envolvidas cultural e socialmente em todas as práticas de uso da língua. Para Jung (2007):

[...] Vale destacar que o termo letramento surgiu para resgatar a ideia pluralista da aquisição e uso da leitura e da escrita na sociedade, ou seja, as pessoas usam a leitura e a escrita em diferentes domínios sociais, com diferentes objetivos, interagem de forma diferenciada com o texto escrito, enfim, somente um conceito em termos de eventos e práticas sociais é capaz de abarcar toda a dinamicidade que envolve um evento no qual um texto escrito constitui parte essencial para fazer sentido nas situações modernas (JUNG, apud CORREA, D. A.; SALEH, P.B.O., 2007, p. 90).

Dialogando com a ideia de Jung (2007), Freire (1985, apud Cavalcante Junior, 2009, p. 35), reflete que "ensinar a ler vai muito além do exercício de codificação e decodificação de palavras; o ensino da leitura pressupõe, necessariamente, ensinar o aluno a ler o seu mundo", uma ação que ultrapassa a decodificação e insere o sujeito nas práticas sociais de uso do cotidiano, como agente do discurso.

Buscando o embasamento teórico para essa pesquisa, bem como o suporte conceitual necessário para esse novo olhar sobre o adulto não alfabetizado, foi necessário pensar em letramentos que, além da palavra, desse conta de tomar por base as práticas sociais, nos aspectos culturais, políticos e econômicos em que cada sujeito está envolvido e nos diversos motivos pelos quais foram privados do domínio escolarizado da leitura e da escrita. Pensar em um conceito que expandisse qualquer conceituação pragmática e rasa da relação do sujeito com o código escrito e a todas as relações, que circulam em torno dele, é expandir a ideia de Letramento, definida por Soares (2001), citado por Jung (2007, p. 84), como "o conjunto de práticas sociais ligadas à leitura e à escrita em que os indivíduos se envolvem em seu contexto social".

Práticas essas que ocorrem atualmente (in) dependentemente do domínio ou não das normas de leitura e da escrita normatizada, como apontado por Tfouni:

[...] é o fato de o letramento poder atuar indiretamente, e influenciar até mesmo culturas e indivíduos que não dominam a escrita. Esse movimento mostra que o letramento é um processo mais amplo que a alfabetização, porém intimamente relacionado com a existência e influência de um código escrito. Assim, culturas e indivíduos, ágrafos ou iletrados, são somente os pertencentes a uma sociedade que não possui, nem sofre, a influência, mesmo que indireta de um sistema de escrita (TFOUNI, 2010, p. 39)

Partindo desse pressuposto, conceitua a autora: “[...] letramento, para mim, é um processo, cuja natureza é sócio-histórica” (TFOUNI, 2010, p. 32), esse processo socio-histórico do letramento se apresenta por meio de normas e costumes que podem ser nomeados como práticas de letramento. Portanto, o letramento está intimamente associado às práticas que os sujeitos realizam em determinado momento histórico em dado contexto social em que esse sujeito passa a agir como protagonista de suas próprias escolhas políticas e sociais tornando-se um agente de transformação.

\section{Leitura, escrita e cidadania}

Os homens se modificam na convivência uns com os outros. Neste processo de convivência e interação com os sujeitos e os objetos que o cercam, o ser humano faz uso do reconhecimento gráfico (e simbólico) a que chamamos em nossa sociedade de Leitura e Escrita, dois processos operatórios que se concretizam na cultura pelo uso real da língua.

Aquilo que compreendemos com as relações sociais integradas aos processos de construção das culturas e sociedades, em que os sujeitos estão envolvidos, representa uma leitura 
inicial, que realizamos antes mesmo do domínio dos signos escritos. Para Freire (2011 apud OLIVEIRA e PRADOS, 2014), o indivíduo, antes de adquirir a leitura da palavra, já tem a leitura do mundo, mas esta só se completa e se descortina ao sujeito se este tem o domínio da palavra.

A leitura [está] no campo individual e se caracteriza como sendo a decodificação de signos linguísticos e ainda como um processo de compreensão mais abrangente em que o leitor dá o sentido a esses signos, assim a leitura é um processo de compreensão de expressões formais ou simbólicas, não importando por meio de que linguagem (MARTINS, 2006, p; 30 apud OLIVEIRA e PRADOS, 2014). Mesmo diante de toda a modernidade, na qual estamos inseridos, podemos observar que a leitura continua sendo processo importante para a compreensão dos aspectos culturais aos quais o homem está envolvido.

Ler pressupõe ativar uma série de mecanismos linguísticos, sociais, culturais e emocionais que são acionados a fim da real compreensão do objeto ou da situação lida pelo sujeito. Silva (2005) realiza reflexões acerca desse processo de leitura no mundo em que vivemos e nos traz algumas definições diante da realidade educacional brasileira do que viria a ser leitura:

\footnotetext{
1. É uma atividade essencial a qualquer área do conhecimento e mais essencial ainda a própria vida...

3. Um dos principais instrumentos que permite ao Ser Humano situar-se com os outros, de discussão e de crítica para se poder chegar al práxis.

5. Possibilita a aquisição de diferentes pontos de vista e alargamento de experiências, parece ser o único meio de desenvolver a originalidade e a autenticidade dos seres que aprendem (SILVA, 2005).
}

Assim como Freire (2011 apud OLIVEIRA e PRADOS, 2014) e Martins (2006 apud OLIVEIRA e PRADOS, 2014), Silva apresenta-nos definições de leitura que perpassam caminhos relevantes. Em um deles, o autor traz a ideia de leitura como algo essencial principalmente para a vida, realizando breve referência às práticas envolvidas nesse processo pelo indivíduo enquanto sujeito de dada sociedade, agente de sua história.

Em uma segunda abordagem, retoma a ideia de leitura como parte do processo da linguagem, aos quais todos nós, sujeitos, estamos envolvidos enquanto modificadores uns dos outros e do mundo que criamos. Finalizando com a ideia desta, como processo de aquisição de conhecimento. Destaca ainda, o pressuposto de que ao experenciar a leitura, o indivíduo executa $\mathrm{o}$ ato de compreender o mundo.

Em relação à escrita datada entre 3000 mil e 4000 mil anos e que Bottéro (1995) define como o sistema de sinais próprios para codificar e fixar todas as mensagens - tudo o que passa pelo espírito que anteriormente era limitada em signos e não traduzia tudo que se passava na mente humana, hoje é o centro de todas as atividades pensadas e está inserida em quase todas as práticas sociais dos sujeitos - teve como berço a antiga mesopotâmia, e foi chamado de "cuneiforme". Foram eles, os mesopotâmicos, os responsáveis pela "invenção" (BOTTÉRO, 1995) do que futuramente viria a ser base para as escritas ocidentais, ascendendo da oralidade para a escrita, atividades do cotidiano dos sujeitos.

A partir de estudos importantes realizados na área, segundo Bottéro, passamos a:

\footnotetext{
Descobrir as diferenças profundas que separam não só discurso escrito do oral, não só o indivíduo capaz de materializar o seu pensamento do analfabeto, mas também... as diferenças [que] separam culturas de tradição escrita daquelas dedicadas apenas à oralidade (BOTTÉRO, 1995, p. 9).
}

Diferenças, que foram importantes para compreendermos de que forma essas sociedades vivenciavam suas práticas sociais entre os indivíduos que faziam uso dela, desde aqueles que possuíam o seu amplo domínio, até os que buscavam outras estratégias. Sobre esse ponto de vista, a prática da leitura e da escrita passam a ser vistas como indissociáveis (BOTTÉRO, 1995, p 19), ou seja, estão interligadas culturalmente. 
Passados os tempos, a escrita foi responsável por uma verdadeira revolução na comunicação. Bottéro realiza indagações interessantes sobre essa revolução da escrita destacando os aspectos do discurso oral e do escrito. Segundo ele, discurso oral implica a presença simultaneamente, no tempo e no lugar da boca que fala e dos ouvidos que ouvem (BOTTÉRO, 1995, p. 21). Enquanto a língua oral faz-se completa apenas com a presença do sujeito orador e aquele que deve receber a informação, o escrito, uma vez fixado, pode por si mesmo, ser difundido por inteiro em todos os lugares e todos os tempos, em toda parte onde encontra um "leitor" (BOTTÉRO, 1995, p 21).

Historicamente as sociedades passam por transformações. Na sociedade moderna não é diferente. Compreender o contínuo dinamismo, modificações e inserções que ocorrem para seu desenvolvimento e melhoramento social, perpassa necessariamente os pressupostos diversos de uso da língua, seja qual for sua modalidade. Durante os anos, por muito tempo e inclusive até hoje, faz-se a associação direta entre analfabetismo, com a perda da cidadania do homem, ou ainda com a alfabetização, como meio de aquisição desse aspecto. Seria essa uma visão simplista, ingênua e arbitrária dos processos constitutivos de uso da língua e da linguagem na sociedade em que vivemos.

Para Soares (2005), o acesso à leitura e à escrita não é imprescindível ao exercício da cidadania, nem mesmo à conquista desta, o que pode ser surpreendente para muitos de nós, se analisado sobre um ponto de vista dualista e binário. A autora nos apresenta os verdadeiros fatores de impedimento de uma vivência plena dos diretos de um cidadão ao revelar as "[...] estruturas privatizantes do poder, os mecanismos de alienação e de opressão, tudo isso resultando na distribuição diferenciada de direitos sociais, civis e políticos às diversas classes e categorias sociais" (SOARES, 2005, p.56).

Essa relação com a vivência da cidadania, concebida como a consciência dos direitos e deveres de cada um, ela se dá de maneira inversamente proporcional ao domínio das normas de leitura e escrita de dada sociedade. No entanto, o que vemos é o contrário, são os mecanismos que impedem essa associação para o exercício dos plenos poderes democráticos.

$\mathrm{Na}$ realidade, a perda de ações de cunho político, distantes de serem produtos da "ignorância" ou da falta de domínio da escrita causada pelo analfabetismo é um produto da falta de equidade entre os sujeitos no meio social, que perpassam tantos outros aspectos, fora o domínio da norma padrão. As conquistas alcançadas por sujeitos analfabetos ocorreram graças às práticas sociais e políticas, por movimentos de ação e reinvindicações sociais que são claramente aspectos dessa formação política do povo, fazendo-se cidadão enquanto luta por seus direitos. A tardia conquista do voto pelo analfabeto é uma conquista desse movimento de representatividade que escorrega diante do domínio da escrita e da leitura e penetram aspectos extremamente sociais e políticos do meio cultural em que estão inseridos.

Freire propõe uma reflexão entre cidadania e alfabetização, para ele:

É a consequência de uma reflexão que o homem começa a fazer sobre sua própria capacidade de refletir. Sobre sua posição no mundo. Sobre o mundo mesmo. Sobre o seu trabalho. Sobre seu poder de transformar o mundo. Sobre o encontro das consciências. [...] Só assim a alfabetização tem sentido. $\mathrm{Na}$ medida em que o homem, embora analfabeto, descobrindo a relatividade da ignorância e da sabedoria, retira um dos fundamentos para a sua manipulação pelas falsas elites. Só assim a alfabetização tem sentido (FREIRE, 1975 apud SOARES, 2005).

Logo, mais que um processo anteriormente apresentado de aquisição dos conhecimentos práticos de leitura e escrita, para Freire a alfabetização constitui-se como um lugar político ocupado pelos sujeitos dentro de suas práticas diárias de fazer cultura e de transformação da sociedade, fazer esse que se expande e sobressai ante as necessidades cada vez mais incisivas de domínio de práticas de escrita e de leitura, que não podem e nunca serão abarcados unicamente pelos signos linguísticos. 
Cabe destacar um aspecto fundamental das novas sociedades, influenciado diretamente por essa relação, como afirma Soares,

As sociedades modernas, porém, são fundamentalmente grafocêntricas; nelas, a escrita está profundamente incorporada à vida política, econômica, cultural, social, e é não só enormemente valorizada, mas, mais que isso é mitificada (é frequente, por exemplo, a suposição de que na escrita é que está o discurso da verdade, que só a escrita é repositório do saber legítimo) (SOARES, 2005, p. 58).

Essas mudanças, eminentemente presentes em sociedades modernas, demandam do sujeito analfabeto não apenas o domínio de códigos linguísticos, que unidos, formam seu próprio nome, como ocorria anteriormente, é preciso fazer uso da leitura e da escrita como prática social, usar a língua no seu dia a dia, o que não necessariamente está ligado ao domínio da técnica da leitura e da escrita. A esse fenômeno foi chamado letramento, que é, pois, o resultado da ação de ensinar ou de aprender a ler e escrever: o estado ou a condição que adquire um grupo social ou um indivíduo como consequência de ter-se apropriado da escrita. (SOARES, 2005, p. 18).

Apropriar-se da escrita não quer dizer necessariamente ser alfabetizado. Crianças que folheiam livros e entendem que aquelas informações possuem um valor social, ou sujeitos analfabetos que se interessam por ouvir a leitura de jornais por pessoas letradas, ou ainda, ditar cartas para que um alfabetizado escreva para ele, podemos dizer que de certa forma esses sujeitos são letrados, e fazem uso da escrita em suas práticas sociais, compreendem a escrita como processo importante de modificação social e fazem o uso dela para facilitar suas práticas cotidianas.

\section{Aspectos metodológicos}

Nesse sentido e com base no quadro teórico acima apresentado, analisamos quatro (4) situações do cotidiano vividas por dois (2) sujeitos/participantes em situação de letramentos diversos, por meio de uma abordagem qualitativa de cunho exploratório.

Os participantes envolvidos nesta investigação foram dois adultos, com mais de trinta anos, que tivessem pouco ou nenhum contato com a escolarização e que pudessem relatar sua experiência quando foram expostos a ambientes como ida ao banco, às compras, à farmácia, entre outros.

A coleta de dados desta investigação utilizou-se da técnica de gravação de relatos, mediada pelos pesquisadores, através de perguntas sobre o cotidiano desses participantes e a utilização da linguagem, para interpretar como os letramentos são operacionalizados por adultos não alfabetizados. Toda essa ação foi realizada a partir do celular (Smartphone, ASUS 5).

Deixamos claro que toda a coleta de dados seguiu o protocolo ético de uso de termo de consentimento aos entrevistados. Lembramos ainda que os nomes são fictícios e apenas dois relatos foram registrados na análise que se segue.

\section{Análise e discussão dos dados}

Essa seção é apenas um recorte da transcrição das falas dos participantes para fim da análise e da discussão. Para tanto, identificaremos P - pesquisador; JDM - participante 1 e NS participante 2. Iniciaremos pela situação 1 - Banco, vejamos o que os sujeitos responderam:

Situação 1 - Banco JDM

P: A senba, a senhora lembra de cor?

JDM: Lembro, eu lembro a senba.

P: Lembra?

JDM: Mais eu, quando eu vou tirar, en dou com tudo, a senha e tudo.

P: Mas se a senbora perder essa senha? 
JDM: Eu sei por cabeça

Situação 1 - Banco NS

P: Mas quando o senhor vai, o senhor leva ela... (a senha)

NS: Não, já levo na cabeça mesmo... Agora eu nem tô precisando mais de senha, mais porque agora e só botar a mão.

Como observamos, parece claro que o processo de memorização está nesses casos intrinsicamente ligados à prática de letramento desses sujeitos. No caso de "JDM: Eu sei por cabeça", referindo-se a senha do banco e "NS: Não, já levo na cabeça mesmo", igualmente, isso mostra como nos inserimos nas práticas sociais relacionando o que aprendemos com situações da vida. Neste sentido, pessoas pouco letradas se inserem nas práticas sociais operacionalizando os letramentos pela memorização de dados.

Isto faz lembrar Ecléa Bosi, ao abordar a Memória partilhada, na obra Tempo vivo da memória: ensaios de psicologia social (2003), quando a autora utiliza da capacidade da memória para nos contar o que nos liga às coisas, aos lugares, às pessoas. Da mesma forma, estabelecemos essa relação com a ação dos participantes desta pesquisa ao utilizarem da memória para se incluírem no mundo dos letramentos.

Em Tomaz (1993, apud BARBOSA, 2005, p. 16) encontramos a definição de memória como "[...] a capacidade de adquirir, reter e recuperar informações de forma consciente ou inconsciente quando necessário. É composta de múltiplos sistemas independentes que funcionam de forma cooperativa". Como se observa os conceitos e os relacionando à situação 1, mesmo sem dar conta do suporte escrito, esses sujeitos não se sentem excluídos da sociedade porque pela memorização conseguem atuar nas práticas sociais que naturalmente fariam uso da linguagem, recorrendo, com certa frequência, à recuperação dessa informação da senha, a partir da capacidade de retenção em seu cérebro, processo esse que ocorre por diversos sistemas, que não necessariamente são os escritos, mas que no caso dessa pesquisa dependem de suas práticas sociais.

Continuando, vamos perceber na situação 2 - dia de compras e 3 - pegar ônibus, no que se refere ao sujeito JDM, ao fazer uso de um mesmo processo de operacionalização de letramento:

Situação 2 - Compras JDM

P: E aí, como a senhora reconhece ele (o produto) lá?

JDM: Porque eu vou, eu já sei a primeira letra do Chinês (referência à marca do arroz).

P: E as outras coisas?

JDM: Café, açúcar eu já sei.

Situação 3 - Ônibus JDM

P: Mas como a senhora reconbece a placa?

JDM: Porque a praca, eu conheço a praca aí tem o nome ali, ai eu vou juntando, ai Henrique Leite (o ônibus), aí eu pego

P: A senhora vai pela, pela...(foi interrompido pela entrevistada)

JDM: A primeira letra do ôibu.

Seria esperado em "JDM: Porque eu vou, en já sei a primeira letra do Chinês" e em "JDM: Porque a praca, eu conheço a praca aí tem o nome ali, ai eu vou juntando, ai Henrique Leite (ônibus), ai eu pego" um processo de estabelecimento de relações entre sons e símbolos gráficos, ou entre fonemas e grafemas (SOARES, 2003, p. 21 apud SILVA, 2010, p.37) o que, no entanto, não ocorre devido ao não domínio da norma padrão escrita por parte desses sujeitos que "interpretam o significado da palavra de acordo com o seu conhecimento prático" (TFOUNI, 2006, p. 54). 
Existe um processo de reconhecimento escrito, típico de sujeitos que realizam suas práticas a partir do uso, ou seja, da repetição de uma mesma situação. JDM usa sempre a mesma marca de arroz e faz uso do mesmo trajeto no transporte público, o que facilita o reconhecimento gráfico das letras usadas nessas situações. Sendo assim, percebe-se, nas situações descritas, que JDM realiza o reconhecimento gráfico de letras para conseguir realizar as ações do seu cotidiano. Com isso, pode-se considerar que, no caso de alteração da tipificação das fontes referentes a essas marcas, poderia atrapalhar a interpretação por parte do sujeito na compreensão total da marca usada ou do ônibus referente.

Temos nessa situação uma construção essencialmente pragmática ao uso da norma escrita, que segundo Tfouni: "a natureza dos metaprocedimentos utilizados por essas pessoas é diferente, estando mais ligados ao conhecimento pragmático e às regras que fundamentam os usos cotidianos do discurso, em situações comuns de comunicação" (TFOUNI, 2006, p. 123).

Apesar de serem construídos mecanismos de operacionalização de letramentos distintos e independentes do domínio da leitura e da escrita, podemos identificar, na descrição das falas dos participantes dessa pesquisa, a valorização da norma escrita, na situação 1- Banco e 4 - Farmácia, abaixo:

Situação 1 -Banco JDM

JDM: Lembro, eu lembro a senha.

P: Lembra?

JDM: Mais eu, quando en vou tirar, en dou com tudo, a senha e tudo.

Situação 4 - Farmácia JDM

P: Como, a senhora, costuma comprar um remédio na farmácia?

JDM: Eu levo a receita... É eu só compro com receita.

Situação 4 - Farmácia NS

NS: Ab! o seguinte é esse, quando for comprar o remédio, tem que levar o nome... É só o nome e pronto.

P: $O$ nome anotado?

NS: Anotado na mão ou no papelzinho.

Podemos observar que, mesmo dispondo de outros mecanismos que não dependem do domínio da modalidade escrita da língua para realizar essas práticas sociais, os sujeitos pesquisados ainda buscam maneiras de fazer uso dessa modalidade. Isso ocorre porque mesmo a linguagem escrita constituindo-se, num segundo nível de mediação entre o cognitivo e o social, em um simbolismo de segunda ordem (VYGOTSKY, 1984, p. 131 apud TFOUNI, 2006, p.42), ela possui um prestígio social relevante.

Como no caso de JDM, na situação do banco, que mesmo consciente e segura de qual é a senha, ela leva anotada: "JDM: Mais en quando en vou tirar, en dou com tudo a senha e tudo". O mesmo ocorre na situação em que o sujeito vai comprar medicamento, momento em que um suporte escrito externo é usado, como exemplifica a fala: "JDM: Eu levo a receita... É en só compro com receita". Mesmo sem possuir qualquer relação que os aproximassem, o participante JN apresenta a mesma necessidade na situação de compra na farmácia, descrita em: "NS: Anotado na mão ou no papelzinho"

As transformações históricas, sociais e políticas no mundo colocaram a escrita em um patamar superior a todas as outras possibilidades de uso da língua oral ou mecanismos distintos desse. Assim, como afirma Soares (2005, p. 58), "é frequente, por exemplo, a suposição de que na escrita é que está o discurso da verdade, que só a escrita é repositório do saber legítimo".

Além dos mecanismos de operacionalização do letramento desenvolvidos pelos sujeitos pesquisados para vivenciar as atividades do cotidiano que demandariam certo domínio das normas da língua, já apresentadas acima, e que em determinado nível se situam dentro do campo da linguagem, podemos detectar estratégias construídas por eles que vão além dos limites da 
língua e se constituíram como novas possibilidades de ver o mundo e o uso que podemos fazer dele para compreender os usos normatizados da língua em todas as suas modalidades. Estratégias essas que vão desde a organização do espaço físico, até demarcadores estruturais.

Vejamos o que ocorre nas próximas situações:

Situação 2 - Compras JDM

P: Como a senhora sabe o que vai comprar?

JDM: Primero é feijão, depois é arroz eu vou tudo pelos preço.

P: Vai pelos preços, não é?

JDM: Os prę̧o eu sei

Situação 2 - NS

P: Não tem aquele especifico (referência ao produto)?

NS: Tem não...Pode ser fino, pode ser grosso.

Na situação 2 - Compras JDM, podemos perceber que o sujeito, desprovido do domínio da norma para a leitura dos produtos no supermercado, passou a dividir sua estratégia de compras em dois sentidos: o primeiro, presente em: "JDM: Primero é feijão, depois é arroz eu vou tudo pelos preço", refere-se à disposição dos alimentos no supermercado. Existe uma ordem para a compra, ela não ocorre de maneira desorganizada, enquanto a segunda, refere-se aos valores de cada produto que é usado como parâmetro para aquisição do mesmo.

Ainda fazendo referência ao sujeito JDM, já em outra situação de compra e consumo de remédios, observa-se a aplicação de duas outras estratégias, inicialmente por não saber ler para ter certeza de que o produto adquirido foi o adequado. Para tanto, ela utiliza da estratégia de comprar a partir do que já secou, como identifica em sua fala: "JDM: ... primeiro en levo o que já secou, aí eu peço". Já em uma operacionalização ainda mais abstrata e arbitrária em relação à língua, JDM identifica a medicação que deve ser ingerida por ela, a partir da organização espacial dos remédios em um dado campo físico, afirmado: "JDM: Eu coloco o de pressão de um lado e o de depressão de outro (fazendo referência ao outro lado da cama)".

O participante NS, ele não tem o domínio da norma para identificar qual a marca de determinado produto para consumir, e ainda, não se atentando a esse aspecto, constrói um sistema de identificação para a escolha do produto na Situação 2 a partir de um aspecto físico do produto, como demostrado na fala: "NS: Tem não...Pode ser fino, pode ser grosso".

Todos esses mecanismos podem ser compreendidos como Extralinguísticos, que em seu sentido mais amplo, o termo se refere a qualquer coisa do mundo (que não seja a língua) em relação à qual a língua está sendo usada, constituindo, assim, uma 'situação extralinguística' (L. DE SOUZA, 2011). Nesse sentido, compreendemos que as situações de fala, ao relacionar aos produtos e seus aspectos, são situações extralinguísticas que funcionam como mecanismos de operacionalização do letramento social dos sujeitos independente da escrita e ancorado nas suas vidas práticas.

Como podemos concluir, mesmo marginalizados e excluídos pelo sistema grafocêntrico, os sujeitos pesquisados conseguiram, através de diversos mecanismos de operacionalização dos letramentos, construir um letramento que se faz, não a partir da escrita ou da leitura da palavra, mas sim da experiência das práticas realizadas por eles perante o mundo.

O que acontece é que alguns sistemas de operacionalização estão indiretamente associados à linguagem, como visto nas análises iniciais de memória e reconhecimento gráfico, fato esse que pode ser compreendido porque "muitas vezes, esse conhecimento não-letrado está impregnado pelo conhecimento letrado, devido ao próprio fato de esses sujeitos viverem em uma cultura perpassada por valores, normas e verdades "científicas", produtos da escrita" ( TFOUNI, 2006 , p. 133) que acabam por influenciar a maneira como eles constroem o mundo. Contudo, muitos outros mecanismos, como os extralinguísticos, distanciam-se completamente da escrita e nascem da real necessidade de organização do sujeito. 
Portanto, ao contrário do que poderia ser imaginado por falantes da Língua, estudiosos ou leigos no assunto, adultos não alfabetizados, mesmo sem possuir o domínio da norma escrita usada pela sociedade em que estão inseridos, constroem seu próprio letramento, como pode ser verificado na análise citada acima. Esses letramentos construídos por esses sujeitos concretizamse na sociedade por meio de diversos mecanismos ligados às suas práticas e aos usos que eles fazem de determinada modalidade da língua.

O primeiro deles é a Memorização, mecanismo que possibilita ao sujeito a realização de práticas a partir do armazenamento de determinada informação pelo cérebro. O segundo é o Reconhecimento Gráfico, que ocorre a partir da memorização de determinado aspecto gráfico da língua - como cor, letra ou símbolo - usado de forma prática no cotidiano e o terceiro, a situação Extralinguística que corresponde à mecanismos distintos de organização do mundo indo desde a organização espacial de determinado objeto até o seu aspecto físico.

Cabe ressaltar, por estarem interseccionados por uma cultura centrada na leitura e na escrita, os sujeitos, na construção de seus letramentos, são influenciados por essa cultura no momento dessa construção, como acontece no primeiro e no segundo mecanismos, que podem ser associados, de um modo distante, à Língua normatizada como a conhecemos. No entanto, não pode ser compreendido como mecanismos que não se integram com o processo de leitura e escrita, porque intimamente há uma relação associativa que é estabelecida. Com relação ao mecanismo 3, embora distante completamente da língua, não da linguagem, é construído a partir de simbologias e gráficos, o que constitui uma situação extralinguística.

\section{CONSIDERAÇÕES FINAIS}

Com base nos estudos de Soares (1999 e 2005), Cavalcante Jr. (2009), Tfouni (2010) e outros, buscamos esclarecer a operacionalização dos letramentos no cotidiano de adultos não alfabetizados. Nesse sentido, a análise e a discussão dos dados dessa pesquisa nos revelaram de que maneira os sujeitos desta pesquisa operacionalizam os diferentes letramentos em suas práticas sociais.

O presente trabalho nos apresentou como resultado três mecanismos distintos de operacionalização dos letramentos por adultos não alfabetizados, como apresentado na análise de dados, são eles: o processo de memorização; o processo de reconhecimento gráfico e os processos extralinguísticos.

Cada um desses processos é acionado por mecanismos distintos e usado em situações específicas pelos sujeitos pesquisados, todos eles se demonstraram arbitrários se levarmos em consideração que se distanciam do domínio da língua escrita, aproximando-se e construindo uma relação com o código escrito como nos dois primeiros processos ou se distanciando completamente deste como no terceiro processo.

Pela observação dos aspectos analisados, os adultos não alfabetizados mesmo não tendo acesso ao processo de escolarização ou alfabetização, eles constroem seus próprios letramentos baseados nas suas práticas cotidianas, podendo esses novos letramentos ser influenciados pela norma escrita ou não, visto que, estando esses sujeitos em uma sociedade grafocêntrica, os letramentos são perpassados pelos valores que são cultivados pela sociedade, como podemos ver nos letramentos extralinguísticos.

Por fim, esse estudo proporcionou uma nova percepção sobre os sujeitos pesquisados, suas práticas de aquisição de letramentos e possibilidades de construção da abordagem sociodiscursiva, além de reconhecer o uso dos letramentos como um processo de inclusão e integração desses sujeitos na sociedade.

\section{REFERÊNCIAS BIBLIOGRÁFICAS}

BARBOSA, José Juvêncio. Alfabetização e Leitura. $2^{\circ}$ Ed. São Paulo: Cortez, 1994. 
BARBOSA, Thais. Memória Operacional Fonológica, Consciência Fonológica e Linguagem nas Dificuldades de Alfabetização. Dissertação (Mestrado em Ciências) - Escola Paulista de Medicina, Universidade Federal de São Paulo. São Paulo. p. 100. 2005.

BOSI, Ecléa. Tempo vivo da memória: ensaios de psicologia social. Ateliê Editorial. 2003.

BOTTÉRO, Jean. Cultura, Pensamento e Escrita: A Escrita e a Formação da Inteligência na Mesopotâmia Antiga. Editora Ática S.A. 1995

CAVALCANTE JUNIOR, Francisco Silva. Letramentos: Por um Mundo Melhor. Campinas, SP: Parábola Aline, 2009. 105 p.

FRADE, Isabel Cristina Alves da Silva. História da Alfabetização e da Cultura Escrita: Discutindo uma Trajetória de Pesquisa. In: MORTATTI, Maria do Rosário Longo (Org.). Alfabetização no Brasil: Uma história de sua História. $2^{\circ}$ Edição. São Paulo, Marília: UNESP, 2012

IBGE, Instituto Brasileiro de Geografia e Estatística. Pesquisa Nacional por Amostra de Domicílios Continua. Editora: IBGE, Coordenação de Trabalho e Rendimento. Rio de Janeiro, 2018, 89 p.

JUNG, M.N. Letramento: Uma Concepção de Leitura e Escrita Como Prática Social. In: CORREA, D. A.; SALEH, P.B.O. (Org.). Práticas de Letramento no Ensino de Leitura, Escrita e Discurso. São Paulo: Parábola Editorial, 2007. p.79 - 106.

L. DE SOUZA, Thais Mannoni (Org.). Glossário de Linguística Comparada: Fundamento de Linguística Comparada. Belo Horizonte: Faculdade de Letras da UFMG, $2^{\circ}$ Semestre.2011.

OLIVEIRA, Antonio Deusivam de; PRADO, Rosália Maria Netto Prados. Educação, Gestão e Sociedade: revista da Faculdade Eça de Queirós: O que é Leitura? Ano 4, número 16, 1 - 5 páginas, Novembro de 2014.

SILVA, Ceris Salete Ribas. Propriedade Intelectual. In Rangel, E. O., ROJO, R.H.R. (Coord.). Lingua Portuguesa: Ensino Fundamental - O processo de Alfabetização no Contexto do Ensino Fundamental de Nove Anos. Brasilia: Ministério da Educação, Secretária de Educação Básica, 2010. 200 p.

SILVA, Ezequiel Theodoro. O Ato de Ler: fundamentos psicológicos para uma nova pedagogia da leitura. $10^{\circ}$ Edição. São Paulo: Cortez, 2005

SOARES, Magda. Alfabetização e Letramento. $3^{\circ}$ Edição. São Paulo: Contexto, 2005 . Letramento: um tema em três gêneros. São Paulo: Autêntica 1999.

TFOUNI, Leda Verdiani. Letramento e Alfabetização. 9 ed. São Paulo: Cortez, 2010. 103 p. . Adultos Não-Alfabetizados em Uma Sociedade Letrada. Ed. rev. São Paulo: Cortez, 2006. 